\title{
Targeting antitumor effect of rhTNF- $\alpha$ fusion protein mediated by matrix metalloproteinase-2
}

\author{
XIN SHAO ${ }^{1}$, HUI REN ${ }^{1}$, YUE-LI WANG $^{1}$, FA WANG $^{1}$, GAN HOU $^{2}$ and DI-NAN HUANG ${ }^{2}$ \\ ${ }^{1}$ Institute of Biochemistry and Molecular Biology, Guangdong Medical College, Zhanjiang, Guangdong 524023; \\ ${ }^{2}$ Department of Clinical Biochemistry, Guangdong Medical College, Dongguan, Guangdong 523808, P.R. China
}

Received September 16, 2014; Accepted October 30, 2014

DOI: 10.3892/or.2014.3616

\begin{abstract}
The aim of this study was to examine the tumor therapy, targeting effects and side effects of tumor-targeting rhTNF- $\alpha$ fusion protein mediated by matrix metalloproteinase- 2 in an animal model in order to provide experimental data for future development of drugs. The median lethal dose $\left(\mathrm{LD}_{50}\right)$ was obtained from acute toxicity experiments. The A549 lung cancer xenograft model was established, and then randomly divided into the saline, standard substance, and low-, middle- and high-dose fusion protein experiment groups. Each group was administered drugs for 18 days. The length and width of the xenografts were measured every three days, after which the xenograft growth curve was drawn. The mice were sacrificed in each group following treatment and the tumor volume and weight were measured. The targeting, effectiveness and toxicity of the transformed fusion protein, and pathological changes of tumor and organ tissues were examined by hematoxylin and eosin (H\&E) staining. Additionally, biochemical markers were used to detect damage of various organs after protein processing. Cell apoptosis and angiogenesis were determined using terminal deoxynucleotidyltransferase-mediated dUTP nick end-labeling (TUNEL) testing and immunohistochemistry, respectively, in different dose groups. Tumor growth was markedly retarded in the high-dose experimental and standard hTNF- $\alpha$ groups with antitumor rates of 85.91 and $72.25 \%$, respectively, as compared with the control group. Furthermore, the tumor tissue showed obvious apoptosis (the apoptotic index was 78.78 and $66.65 \%$, respectively) and pathological changes in the high-dose experimental and standard hTNF- $\alpha$ groups. Tumor angiogenesis in each fusion protein group was inhibited $(\mathrm{P}<0.01)$ and the biochemical markers of various organs were greatly reduced in the high-dose experimental group $(\mathrm{P}<0.05)$. This finding indicated that slight toxic effects of fusion proteins
\end{abstract}

Correspondence to: Professor Gan Hou, Department of Clinical Biochemistry, Guangdong Medical College, No. 1 Xincheng Road, Dongguan, Guangdong 523808, P.R. China

E-mail: houganhwj@126.com

Key words: fusion protein, rhTNF- $\alpha$, lung cancer, target, side effect were evident for the heart, liver and kidney. The reforming fusion protein can therefore target tumor tissues and efficiently kill tumor cells, with few side effects.

\section{Introduction}

Lung cancer is the leading cause of cancer-associated human mortality (1). Non-small cell lung cancer (NSCLC) is the most commonly diagnosed form of the disease accounting for $>85 \%$ of the cases (2). In 2004, 66.7/100,000 individuals succumbed to lung cancer in China $(3,4)$. Chemotherapy and radiotherapy are the main approaches for cancer therapy in addition to surgery. However, due to the lack of tumor specificity, these therapies kill cancer and healthy cells, eliciting severely toxic side effects (5).

Tumor necrosis factor (TNF) was first described for its ability to induce hemorrhagic necrosis in mouse tumor $(6,7)$. Owing to its notable ability to kill tumor cells in vitro or in vivo, TNF- $\alpha$ has potential application value as an antitumor biological preparation (5). Nevertheless, a major obstacle to TNF- $\alpha$ in clinical application is a series of side effects such as fever, nausea and vomiting following frequent injections thereof, which are necessary to achieve the maximum blood drug concentration, particularly the tumor local drug concentration, and the narrow therapeutic window. The proinflammatory activities of TNF- $\alpha$ can provoke a potentially lethal systemic inflammatory response syndrome (SIRS) characterized by hypotension and severe hepatitis (8). Currently, $\mathrm{TNF}-\alpha$ is administered in patients only through locoregional drug delivery systems such as isolated limb perfusion (ILP) and isolated hepatic perfusion (IHP) (9-11). Matrix metalloproteinases (MMPs) play a central role in the breakdown of the extracellular matrix and are typically upregulated in cancer cells (12-14). MMPs are overexpressed in various types of human cancer including NSCLC $(15,16)$. Of all the MMPs, MMP-2 and MMP-9 are important in the process of angiogenic progression. MMP-2 and MMP-9 have been associated with increased tumor spread and poor prognosis in lung cancer (17). A high expression of MMP-2 and MMP-9 in NSCLC was previously identified, demonstrating a potential prognostic role of MMP-9 and MMP-2 in stage 1A NSCLC patients (18). Findings of a meta-analysis support the fact that MMP-2 may be a prognostic factor in further prospective trials studying NSCLC (19). Results of previous studies 
showed that MMP-1, MMP-2 and MMP-9 had a high expression in A549 lung cancer cell lines (20-22). Consequently, the A549 lung adenocarcinoma transplantation tumor model was selected for use in the present study. Considering that MMP-2 was overexpressed in cancer cells, we constructed the fold on-MMP-2-rhTNF- $\alpha$ fusion protein, whose mutant hTNF- $\alpha$ linked a MMP-2 substrate sequence and a fold-on sequence (the fold on the domain of T4 phage fibrous superhelix protein). Theoretically, when a fusion protein reaches tumor tissues, MMPs that are centered in the tissue hydrolyze their substrates. Thus, the receptor binding sites of hTNF- $\alpha$ are exposed, hTNF- $\alpha$ block is disengaged and the active form, or trimer form, of hTNF- $\alpha$ is concentrated in tumor tissue, playing an antitumor targeting role.

In this study, we specifically utilized the MMP-2 substrate sequence to construct a mutant hTNF- $\alpha$ concentrate in tumor tissues. Subsequently, we developed hTNF- $\alpha$ ramification and assessed its efficacy and safety.

\section{Materials and methods}

Cell line and cell culture. A549 lung adenocarcinoma cells were provided by the laboratory of the Guangdong Medical College Institute (Guangdong, China). A549 cancer cells were routinely grown in RPMI-1640 (Life Technologies, Carlsbad, CA, USA) supplemented with $10 \%$ fetal calf serum (Zhejiang Tianhang Biological Technology Co., Ltd., Hangzhou, China) and $1 \%$ antibiotics $(100 \mathrm{U} / \mathrm{ml}$ penicillin, $100 \mu \mathrm{g} / \mathrm{ml}$ streptomycin) (Life Technologies) at $37^{\circ} \mathrm{C}$ in a humidified atmosphere with $5 \% \mathrm{CO}_{2}$ and cultured to logarithmic phase.

Animals. Kunming mice ( $\mathrm{n}=35$ male and $\mathrm{n}=35$ female) and specified pathogen-free (SPF) nude mice $(n=25$ male and $n=25$ female) with an average weight of $20 \pm 2 \mathrm{~g} /$ mouse, were provided by the Experimental Animal Center of Guangdong Medical College. Animal experiments were followed and approved by the institutional guidelines of the Guangdong Medical College.

Drugs and primary instruments. The von Willebrand factor (vWF) antibody was purchased from Novus Biologicals (Littleton, CO, USA). The biochemical indicators kit was purchased from Hefei TianYi Institute of Biological Technology (Anhui, China). A biological microscope (SZ-8D) was purchased from Wuzhou Optical Instrument Factory (Guangxi, China). An optical microscope was purchased from Olympus (Tokyo, Japan). The LX20 automatic biochemical analyzer was purchased from Beckman Coulter (Brea, CA, USA). Other common reagents and instruments were provided by the Institute of Biochemistry and Molecular Biology, Guangdong Medical College.

Acute toxicity experiment in mice. Male and female adult Kunming mice were randomly divided into seven groups (10 mice/group, 5 females and 5 males). The mice were injected fusion protein (extracted by our research group) intravenously at doses of 1,000; 800; 600; 500; 400; 250 and $125 \mu \mathrm{g} / \mathrm{kg}$, respectively. The injection volume of each mouse was $0.2 \mathrm{ml}$. Subsequent to administration, the mice were observed closely during the day, for any toxicity manifestation, such as increased motor activity, salivation, convulsion, coma and death. Subsequently, observations were made twice a day every $12 \mathrm{~h}$. The animals were under constant observation up to a period of 14 days, after which the live mice were euthanized and laparotomy was performed. Heart, liver and kidney were extracted from the mice for pathological examination, and specimens were evaluated histologically.

Establishment of animal model, grouping and injection. The logarithmic phase A549 cells were suspended in a moderate amount of RPMI-1640 medium without serum and antibiotics (100 U/ml penicillin, $100 \mu \mathrm{g} / \mathrm{ml}$ streptomycin). The cell suspension was required to be evenly mixed and with uniform density. The cell density was adjusted to $1 \times 10^{7} / \mathrm{ml}$ following cell count. Under aseptic conditions, $0.2 \mathrm{ml}$ cell suspension was withdrawn by using a $1 \mathrm{ml}$ syringe (Shifeng Medical Apparatus and Instrument, Chengdu, China) and administered to SPF nude mice on their right flank with a slow axillary subcutaneous injection. The long diameters a) and short diameters b) of the subcutaneously-transplanted tumor of each SPF nude mouse was measured using a vernier caliper (Guilin Guanglu Measuring Instrument Co., Ltd., Guilin, China). Tumor volumes were calculated using the formula $\mathrm{V}=1 / 2 \mathrm{ab}^{2}$. Drug administration was initiated when the tumor volume ranged $100-150 \mathrm{~mm}^{3}$.

After the tumor-bearing SPF nude mice model was successfully established, the mice were randomized into the saline group, fusion proteins with high-dose group $(200 \mu \mathrm{g} / \mathrm{kg})$, fusion protein with middle-dose group $(100 \mu \mathrm{g} / \mathrm{kg})$, fusion proteins with low-dose group (50 $\mu \mathrm{g} / \mathrm{kg})$, and standard substance group $(2 \mu \mathrm{g} / \mathrm{kg}$ ) according to the weight ( $\mathrm{n}=10$ mice/group. In each group, mice were administered the drug once on alternate days, with the intratumor injection volume of the standard substance group being $0.1 \mathrm{ml}$ and that of the fusion protein being $0.2 \mathrm{ml}$, consecutively for 18 days. The volume of the subcutaneously transplanted tumor of the SPF nude mice was measured every 3 days. The SPF nude mouse diet, mental state and growth of the transplanted tumor were observed during the period of drug delivery on a daily basis. A growth curve was subsequently drawn based on the tumor volume results.

Treatment of SPF nude mice and tumor. After $24 \mathrm{~h}$ of drug administration, blood was drawn from orbital venous in mice to detect their biochemical indicators, subcutaneous tumor tissue was selected, and hearts, livers and kidneys were extracted. The organs were sliced and stained with hematoxylin and eosin (H\&E). The cell morphology of the viscera was observed to evaluate the side effects of transformed fusion proteins. Tumor tissues of each group were detected by immunohistochemistry. Measurements of the tumor inhibition rate were made using the formula: $\mathrm{R}=\left(1-\mathrm{V}_{1}\right) \times 100 \% / \mathrm{V}_{2}$, where $\mathrm{R}$ is the tumor inhibition rate, $V_{1}$ the average tumor volume of the experimental group, and $\mathrm{V}_{2}$ the tumor volume of the control group.

Immunohistochemical detection of tumor angiogenesis and microvascular density. Tumor tissues were assessed using the immunohistochemical streptavidin-peroxidase (SP) technique, using the Weidner capillary counting method (23) to calculate the microvessel quantity: a low power lens (x100) was used to select three areas with the highest density of blood vessels. At high power (x400), each area was divided four visual fields and the average microvascular number was counted. 
Table I. LD $_{50}$ concerning fusion protein fold on-MMP-2-hTNF- $\alpha$ intravenous drug delivery in Kunming mice (probit method).

\begin{tabular}{|c|c|c|c|c|c|c|c|c|c|c|c|c|}
\hline \multirow{2}{*}{$\begin{array}{l}\text { Dose } \\
(\mu \mathrm{g} / \mathrm{kg})\end{array}$} & \multirow{2}{*}{$\begin{array}{l}\text { Sample } \\
\text { (n) }\end{array}$} & \multirow{2}{*}{$\begin{array}{l}\text { Mortality } \\
\text { (n) }\end{array}$} & \multicolumn{7}{|c|}{ Distribution of death (days) } & \multirow{2}{*}{$\begin{array}{l}\text { Death rate } \\
(\%)\end{array}$} & \multirow{2}{*}{$\begin{array}{c}\mathrm{LD}_{50} \\
(\mu \mathrm{g} / \mathrm{kg})\end{array}$} & \multirow{2}{*}{$\begin{array}{c}95 \% \text { confidence } \\
\text { limit }(\mu \mathrm{g} / \mathrm{kg})\end{array}$} \\
\hline & & & 1 & 2 & 3 & 4 & 5 & 6 & 7 & & & \\
\hline 1,000 & 10 & 10 & 2 & 4 & 2 & 1 & 1 & 0 & 0 & 100 & & \\
\hline 800 & 10 & 7 & 1 & 3 & 2 & 1 & 0 & 0 & 0 & 70 & & 522.0 \\
\hline 600 & 10 & 5 & 0 & 3 & 2 & 0 & 0 & 0 & 0 & 50 & & \\
\hline 500 & 10 & 3 & 0 & 2 & 1 & 0 & 0 & 0 & 0 & 30 & 609.8 & \\
\hline 400 & 10 & 2 & 0 & 2 & 0 & 0 & 0 & 0 & 0 & 20 & & 718.1 \\
\hline 250 & 10 & 1 & 0 & 1 & 0 & 0 & 0 & 0 & 0 & 10 & & \\
\hline 125 & 10 & 0 & 0 & 0 & 0 & 0 & 0 & 0 & 0 & 0 & & \\
\hline
\end{tabular}

MMP-2, matrix metalloproteinase-2; TNF, tumor necrosis factor.

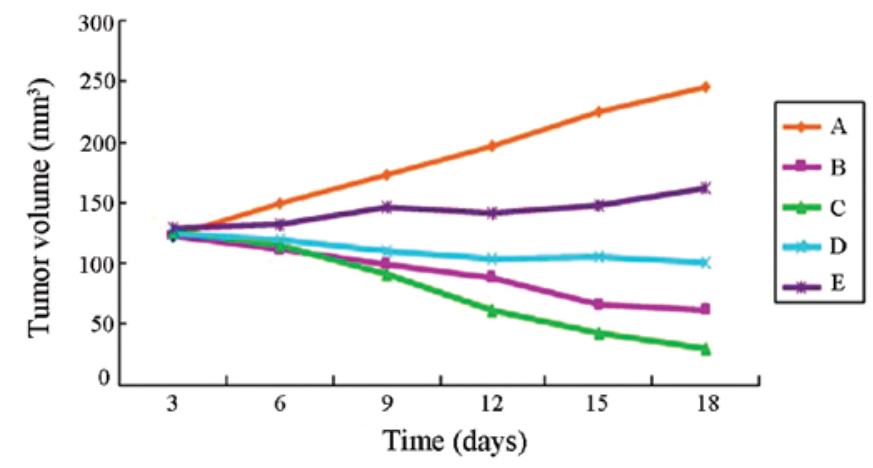

Figure 1. Tumor growth curves for each group of A549 solid tumors The tumor volume was markedly inhibited in the high- and middle-dose experimental groups C and D. (A) Saline, (E) low-dose experimental and (B) standard hTNF- $\alpha$ groups.

In situ detection of apoptosis by TUNEL (apoptosis detection assays). Using the In situ cell death detection kit (Nanjing KeyGen Biotech Co., Ltd., Nanjing, China), sections were examined under a light microscope in randomly selected five high-power fields. The apoptotic index was calculated using in situ labeling of terminal deoxynucleotidyl transferase-mediated nick end-labeling (TUNEL).

Statistical analysis. Data were presented as mean \pm SD and analyzed using SPSS 17.0 statistical software (SPSS, Inc., Chicago, IL,USA) using the formula: Probit $(P)=-2.617+4.291 X$. The Chi-square test was used to determine the goodness-of-fit. Comparisons of the mean of two samples were performed using the t-test, while comparisons of numerous samples was performed using one-way analysis of variance (one-way ANOVA). To determine homogeneity of variances when the population variance was equal the least significant difference (LSD) was employed. By contrast, Tamhane's T2 test was utilized for the unequal variances. $\mathrm{P}<0.05$ was considered statistically significant.

\section{Results}

Acute toxicity experiment results of fusion protein fold on$M M P-2-r h T N F-\alpha$ to mice. Mice in the high-dose groups

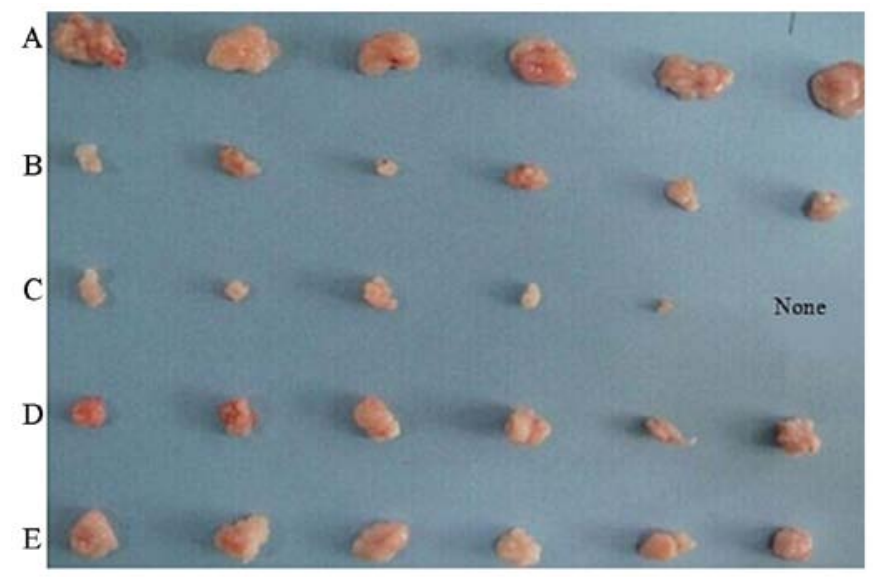

Figure 2. Five groups of A549 solid tumors $(n=6)$. Grossly, treatment with (B) standard rhTNF- $\alpha,(\mathrm{C}$ and $\mathrm{D})$ high- and middle-dose fusion protein resulted in significant growth inhibition compared with the (A) saline group. (E) Low-dose experimental group.

$(1,000,800$ and $600 \mu \mathrm{g} / \mathrm{kg})$ became tachypneic, systemic cyanotic and costive, whereas mice in the low-dose groups $(500,400,250$ and $125 \mu \mathrm{g} / \mathrm{kg}$ ) had no obvious abnormalities. The death time was $\sim 1-5$ days following treatment. The dead animals were dissected and the main organs (heart, liver and kidney) were observed with the naked eye. No obvious pathological changes were identified.

The probit method (Table I) was utilized to analyze data through SPSS 17.0 statistical software using the formula: Probit $(P)=-2.617+4.291 X$. The Chi-square test result showed that Probit $(\mathrm{P})=0.911$ yielded an excellent goodness-of-fit.

Growth inhibitory effect of fusion protein on A549 lung cancer-transplanted solid tumor. The tumor growth curve was drawn based on the marked changes in transplanted tumor volume (Fig. 1). Statistic analysis revealed that the inhibition ratio of the high-dose experimental, standard hTNF- $\alpha$ and middle-dose experimental groups, respectively, was 85.91, 72.25 and $55.66 \%$. Tumor growth was markedly inhibited in the high-dose experimental, standard hTNF- $\alpha$ and middle-dose experimental groups (Table II). Tumor volume and weight were lower than the control group $(\mathrm{P}<0.01)$. In Fig. 2, the result 
A

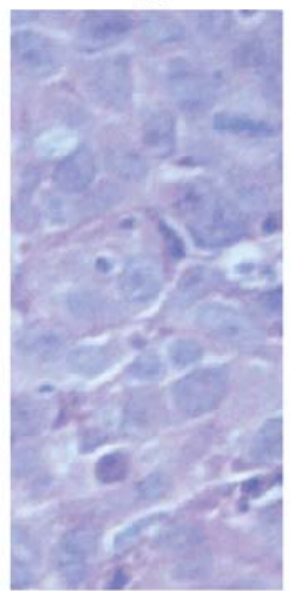

B

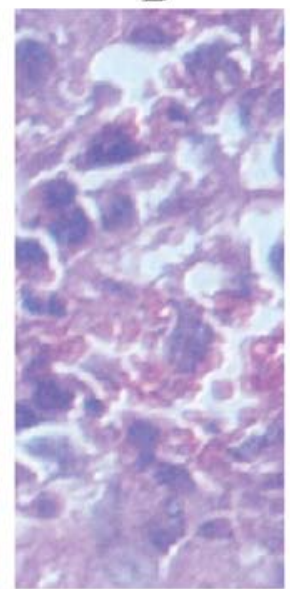

C

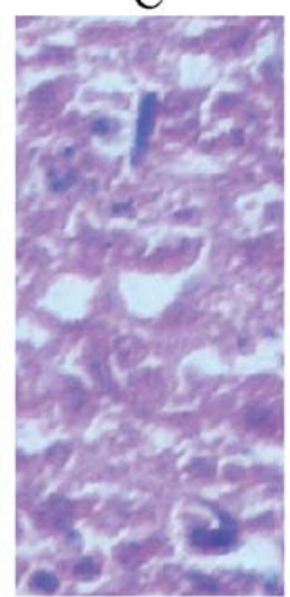

D

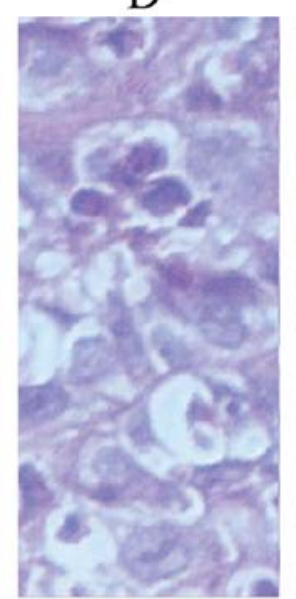

E

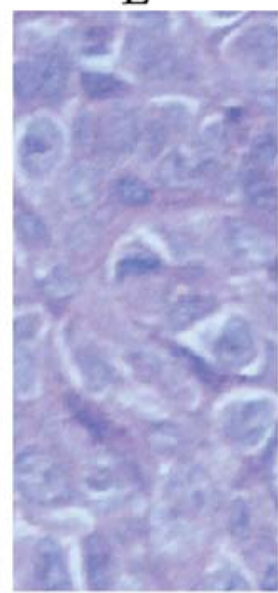

Figure 3. A549-transplanted tumors. Sections were stained with hematoxylin and eosin (H\&E); magnification, $\mathrm{x} 400$. In the (B) standard hTNF- $\alpha$ and (C) high-dose experimental groups, the cells became distinctly necrotic. (A) Saline group, (D and E) middle- and low-dose experimental groups.

A

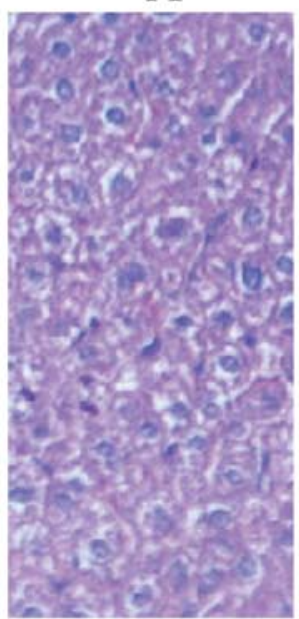

B

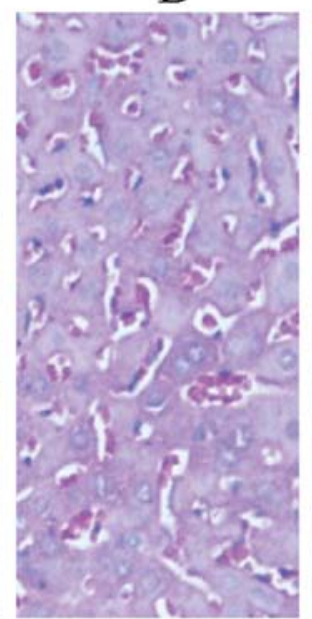

C

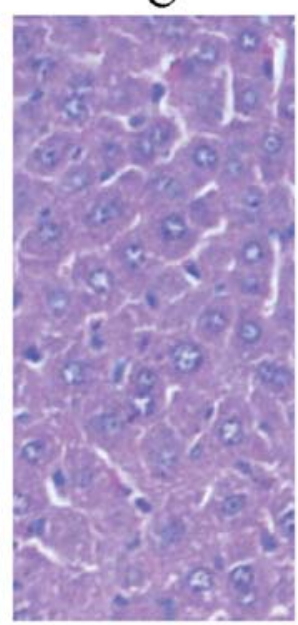

D

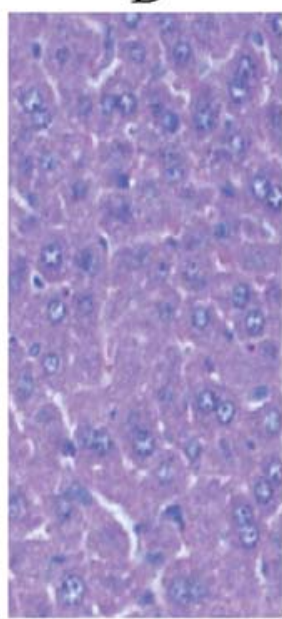

$\mathrm{E}$

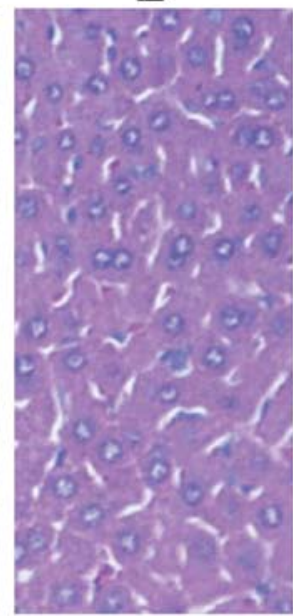

Figure 4. Pathological sections of livers, stained with hematoxylin and eosin (H\&E); magnification, $\mathrm{x} 400$. Compared with the (A) saline group, the cell morphology in the (C-E) high-, middle- and low-dose experimental groups did not markedly change. By contrast, in the (B) standard rhTNF- $\alpha$ group, fusions of hepatocyte, the decrescent nucleus and the congestive hepatic sinusoid with a small amount of infiltrative inflammatory cells were observed.

Table II. The role of fusion protein fold on-MMP-2-hTNF- $\alpha$ to A549 lung cancer solid tumors of nude mice.

\begin{tabular}{lccc}
\hline Groups & $\begin{array}{c}\text { Tumor weight } \\
(\mathrm{g})\end{array}$ & $\begin{array}{c}\text { Tumor volume } \\
\left(\mathrm{mm}^{3}\right)\end{array}$ & $\begin{array}{c}\text { Antitumor } \\
\text { rate }(\%)\end{array}$ \\
\hline A & $0.32 \pm 0.07$ & $245.32 \pm 39.08$ & - \\
B & $0.09 \pm 0.32^{\mathrm{a}}$ & $60.88 \pm 22.10^{\mathrm{a}}$ & 72.25 \\
C & $0.05 \pm 0.35^{\mathrm{a}}$ & $30.40 \pm 22.97^{\mathrm{a}}$ & 85.91 \\
D & $0.14 \pm 0.30^{\mathrm{a}}$ & $100.01 \pm 22.26^{\mathrm{a}}$ & 55.66 \\
E & $0.23 \pm 0.04$ & $162.27 \pm 29.14$ & 29.76 \\
\hline
\end{tabular}

${ }^{\mathrm{a}} \mathrm{P}<0.01$ as compared with saline group. MMP-2, matrix metalloproteinase-2; TNF, tumor necrosis factor.

of the tumor volume for all the groups was consistent with the abovementioned results. A significant dose-dependent association was identified. In the experiments, the mice in the standard hTNF- $\alpha$ group exhibited pupillary dilation and were lethargic. Mice in the fusion protein groups were vigorous and flexibile in action. This result indicated that the toxicity of the fusion protein on mice in the fusion protein groups was decreased as compared to that in the standard hTNF- $\alpha$ group, indirectly proving that fold on-MMP-2-rhTNF- $\alpha$ serves as a good target for the selection of tumor cells.

Effect of fusion protein on tumor tissues. Tumor tissue sections stained with H\&E had a large area of necrosis cells, incomplete cell membranes and karyopyknosis in the standard hTNF- $\alpha$ group (Fig. 3). In the high-dose experimental group, almost all the cells became necrotic. The cell structure disappeared and the necrotic area was red. In the saline and low-dose experimental groups marked tumor cell growth was identified. The cells had coincident size, abundant cytoplasm, and obvious mitotic figure. However, in the middle-dose experimental 


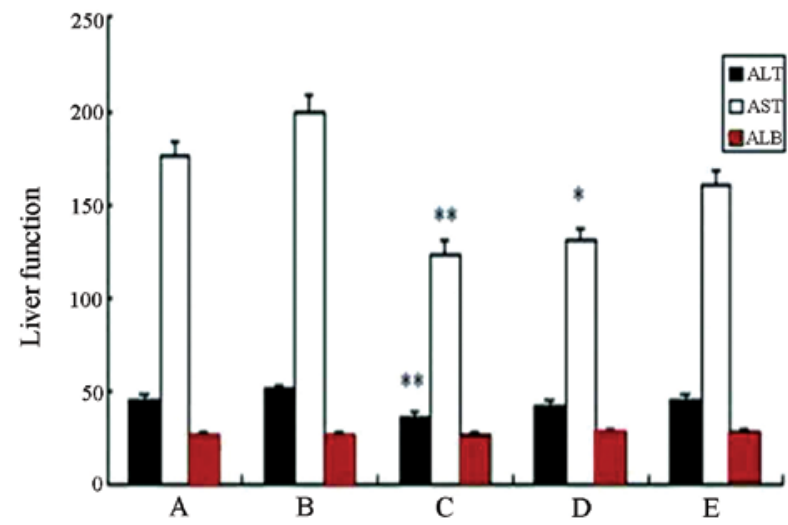

Figure 5. Effect of fusion protein fold on-MMP-2-hTNF- $\alpha$ on hepatic function. (A) Saline group, (C-E) high-, middle- and low-dose experimental groups. ${ }^{* *} \mathrm{P}<0.01$ and ${ }^{*} \mathrm{P}<0.05$, compared with the (B) standard hTNF- $\alpha$ group.
Table III. Measured values of hepatic function of fusion protein fold on-MMP-2-hTNF- $\alpha$ on A549 lung cancer solid tumors of nude mice.

\begin{tabular}{llcc}
\hline Group & ALT (IU/l) & AST (IU/l) & ALB (g/l) \\
\hline A & $45.17 \pm 15.32$ & $175.37 \pm 69.40$ & $27.00 \pm 1.38$ \\
B & $51.12 \pm 10.41$ & $198.93 \pm 49.93$ & $26.93 \pm 1.30$ \\
C & $36.54 \pm 4.93^{\mathrm{a}}$ & $123.67 \pm 20.89^{\mathrm{a}}$ & $27.13 \pm 2.33$ \\
D & $43.31 \pm 12.30$ & $130.30 \pm 32.45^{\mathrm{b}}$ & $27.34 \pm 1.28$ \\
E & $45.40 \pm 8.16$ & $160.77 \pm 72.95$ & $27.89 \pm 1.95$ \\
\hline
\end{tabular}

${ }^{\mathrm{a}} \mathrm{P}<0.01,{ }^{\mathrm{b}} \mathrm{P}<0.05$ as compared with standard hTNF- $\alpha$ group. ALT, glutamic-pyruvic transaminase; AST, aspartate aminotransferase; ALB, albumin; TNF, tumor necrosis factor; MMP-2, matrix metalloproteinase-2.
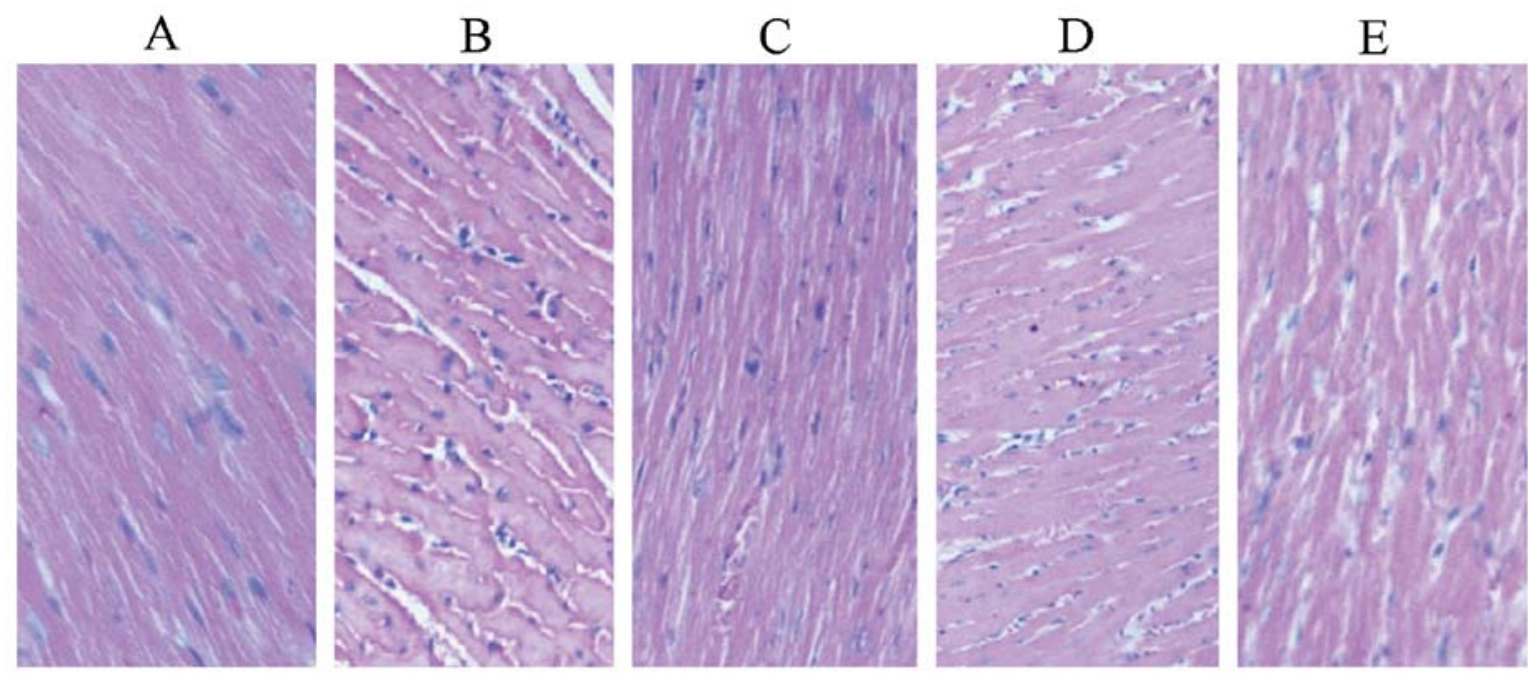

Figure 6. Pathological sections of myocardial tissues, stained with hematoxylin and eosin (H\&E); magnification x400. In the (B) standard hTNF- $\alpha$ group, the structure of myocardial fibers was disorderly. (A) Saline group, (C-E) high-, middle- and low-dose experimental groups.

group, the cells had a disorderly arrangement and had vacuolar degeneration, and an uneven size.

Effect of fusion protein on SPF nude mouse viscera. The perspective of biological enzyme levels and histomorphology concerning the effects of fusion protein on tumor-bearing mouse viscera are analyzed below.

Effects on livers. Fig. 4 shows the pathological sections of livers. In the fusion protein groups, the number of liver cells decreased, the liver plate and liver blood sinus were clear and a radiating arrangement was identified at low magnification, as compared to the saline group.

Serum concentrations of glutamic-pyruvic transaminase (ALT) and aspartate aminotransferase (AST) in the high-dose experimental group were significantly lower than that in the standard hTNF- $\alpha$ group $(\mathrm{P}<0.01)$ (Table III and Fig. 5). The results showed that the effect of fusion protein on the liver injury of tumor-bearing mice in the high-dose experimental group was significantly smaller than of the standard substance of TNF. Compared with the saline group, no significant difference was identified in any of the groups $(\mathrm{P}>0.05)$. Similarly, no significant difference was found in the albumin (ALB) levels, suggesting that the protein synthesis function of liver was not significantly affected by different doses of medication.

Effects on hearts. In the standard hTNF- $\alpha$ group, there was a little congestion between muscle bundles and inflammatory cell infiltration, whereas in the other treatment groups, the myofilaments were dense, ranked neatly and the nucleus was centrally located. No obvious abnormality was found (Fig. 6).

Compared with the saline group, no significant difference ( $>0.05)$ was identified with any of the remaining groups (Table IV). Serum concentrations of lactic dehydrogenase (LD) and creatine kinase (CK) in the high-dose experimental group were significantly lower than those in the standard hTNF- $\alpha$ group $(\mathrm{P}<0.05)$, thus, high doses of fusion protein may play a protective role in myocardial cells. A histogram that visually demonstrated the changing trends of LD and CK among the groups was created (Fig. 7).

Effects on kidneys. In the standard hTNF- $\alpha$ group, cuboidal surface cells of proximal convoluted tubules (PCT) and distal convoluted tubules (DCT) were fused. The nucleus was reduced, while the nephrons were unsound (Fig. 8). 


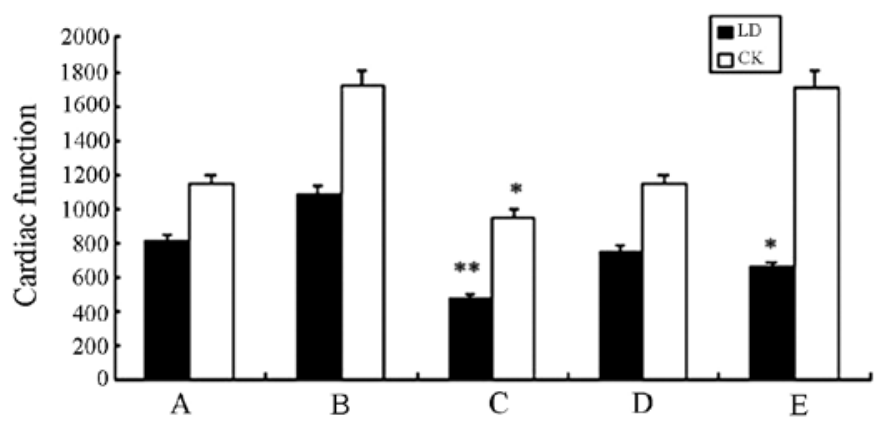

Figure 7. Effect of fusion protein fold on-MMP-2-hTNF- $\alpha$ on lactic dehydrogenase (LD) and creatine kinase (CK). (A) Saline group, (C-E) high-, middle- and low-dose experimental group. ${ }^{* *} \mathrm{P}<0.01$ and ${ }^{*} \mathrm{P}<0.05$, compared with the (B) standard hTNF- $\alpha$ group.
Table IV. Measured values of LD and CK of fusion protein fold on-MMP-2-hTNF- $\alpha$ on A549 lung cancer solid tumors of nude mice.

\begin{tabular}{lcc}
\hline Group & LD (IU/l) & CK (IU/l) \\
\hline A & $809.56 \pm 441.68$ & $1145.87 \pm 466.23$ \\
B & $1080.31 \pm 448.03$ & $1719.54 \pm 425.56$ \\
C & $475.46 \pm 107.54^{\mathrm{a}}$ & $951.51 \pm 171.32^{\mathrm{b}}$ \\
D & $746.61 \pm 260.35$ & $1140.10 \pm 460.50$ \\
E & $656.02 \pm 334.65^{\mathrm{b}}$ & $1715.04 \pm 1100.62$ \\
\hline
\end{tabular}

${ }^{\mathrm{a}} \mathrm{P}<0.01,{ }^{\mathrm{b}} \mathrm{P}<0.05$ as compared with standard hTNF- $\alpha$ group. $\mathrm{LD}$, lactic dehydrogenase; $\mathrm{CK}$, creatine kinase. TNF, tumor necrosis factor; MMP-2, matrix metalloproteinase-2.
A

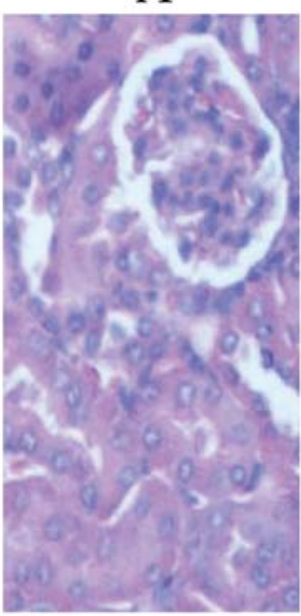

B

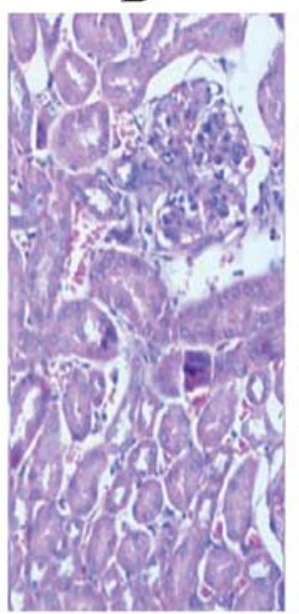

$\mathrm{C}$

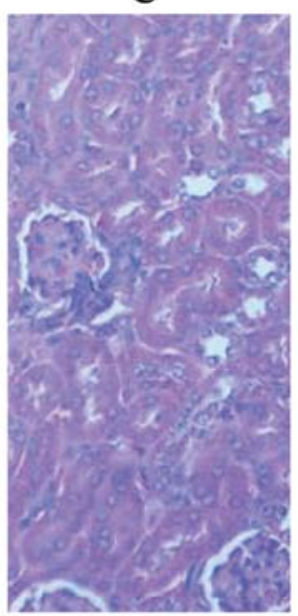

$\mathrm{D}$

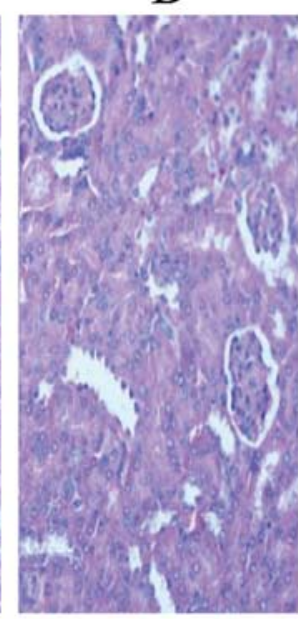

$\mathrm{E}$

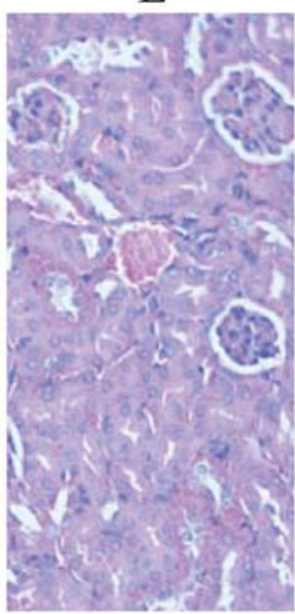

Figure 8. Pathological sections of kidneys, stained with hematoxylin and eosin (H\&E); magnification x400. In the (B) standard rhTNF- $\alpha$ group, glomeruli were of different sizes and their structures collapsed. In the (C-E) high-, middle- and low-dose experimental groups, the nephrons had no significant reduction, the structure of the glomeruli was almost normal, while hyperaemia and inflammation were not evident. (A) Saline group.

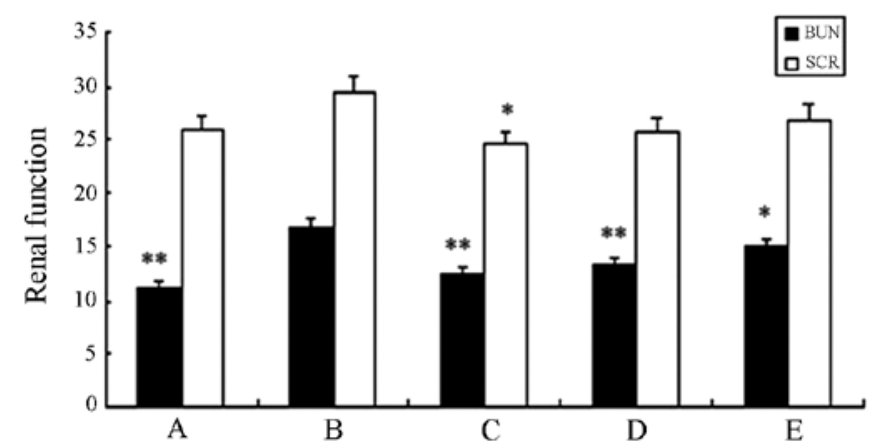

Figure 9. Effect of fusion protein on blood urea nitrogen (BUN) and serum creatinine (SCR). (A) Saline group, (C-E) high-, middle- and low-dose experimental group. ${ }^{* *} \mathrm{P}<0.01$ and ${ }^{*} \mathrm{P}<0.05$, compared with standard hTNF- $\alpha$ group.
Table V. Measured values of renal function for fusion protein fold on-MMP-2-hTNF- $\alpha$ on A549 lung cancer solid tumors of nude mice.

\begin{tabular}{lll}
\hline Group & BUN $(\mathrm{mmol} / \mathrm{l})$ & $\mathrm{SCR}(\mu \mathrm{mol} / \mathrm{l})$ \\
\hline A & $11.17 \pm 1.06^{\mathrm{a}}$ & $25.90 \pm 2.88$ \\
B & $16.84 \pm 2.67$ & $29.50 \pm 3.70$ \\
C & $12.60 \pm 2.17^{\mathrm{a}}$ & $24.53 \pm 3.04^{\mathrm{b}}$ \\
D & $13.27 \pm 1.71^{\mathrm{a}}$ & $25.80 \pm 7.58$ \\
E & $14.92 \pm 1.57^{\mathrm{b}}$ & $26.92 \pm 4.20$ \\
\hline
\end{tabular}

${ }^{\mathrm{a}} \mathrm{P}<0.01,{ }^{\mathrm{b}} \mathrm{P}<0.05$ as compared with standard hTNF- $\alpha$ group. BUN, blood urea nitrogen; SCR, serum creatinine; MMP-2, matrix metalloproteinase-2; TNF, tumor necrosis factor.
Table $\mathrm{V}$ and Fig. 9 show that compared with the saline group, no significant difference $(\mathrm{P}>0.05)$ was identified in any of the remaining groups. The level of blood urea nitrogen (BUN) and serum creatinine (SCR) in the high-dose experimental group showed a statistical significant difference when compared with the standard hTNF- $\alpha$ group $(\mathrm{P}<0.01)$. This result suggested that the fusion protein did not sufficiently affect the nephritic filtration function and no obvious renal damage was identified.

Detection of the fusion protein effect on tumor angiogenesis by immunohistochemistry. We observed the richness and angiogenesis of interstitial blood vessel in all the groups (Fig. 10). 
A

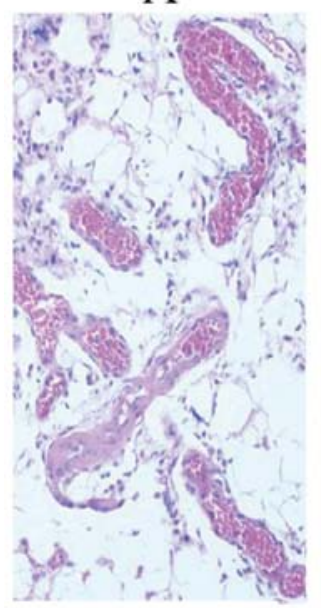

B

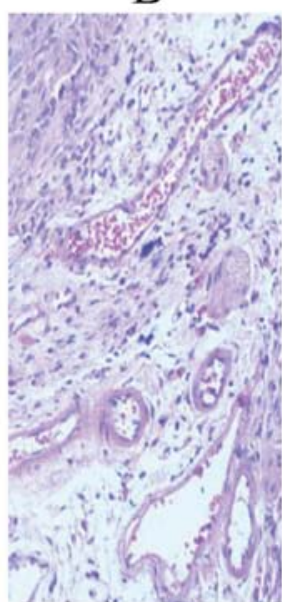

C

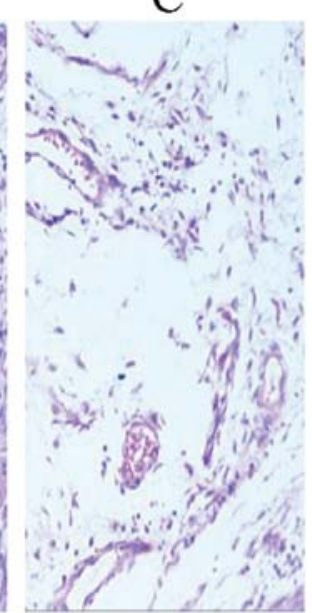

D

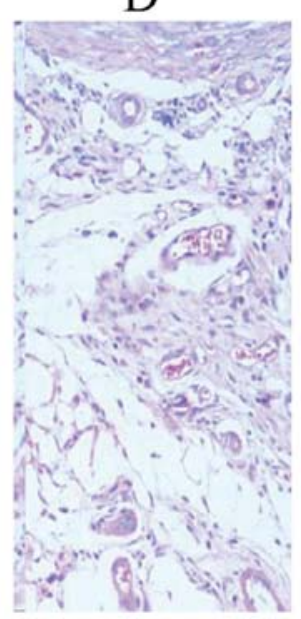

E

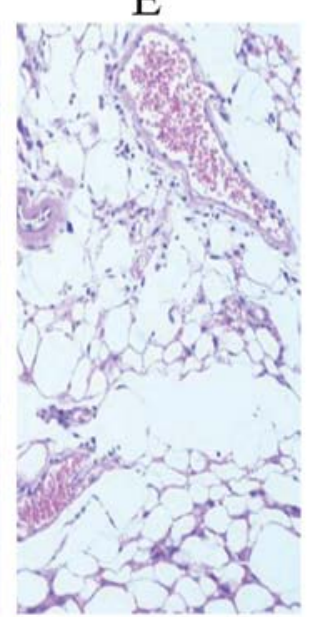

Figure 10. Pathological sections of tumor angiogenesis, stained with hematoxylin and eosin (H\&E); magnification, $x 400$. Tumor interstitial tissue was rich in the (A) saline group, while the number of blood vessels in the (B) standard hTNF- $\alpha$ group and the (C-E) high-, middle- and low-dose experimental groups were decreased.

A

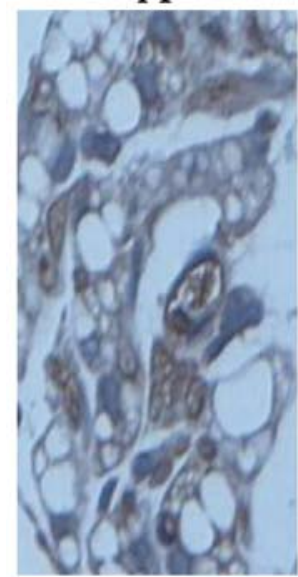

B

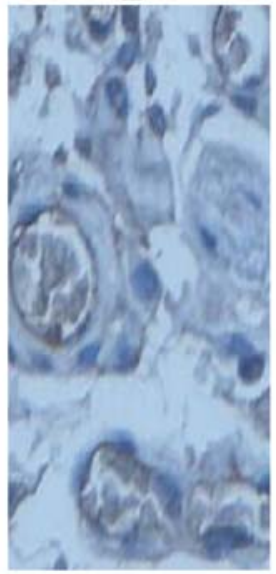

$\mathrm{C}$

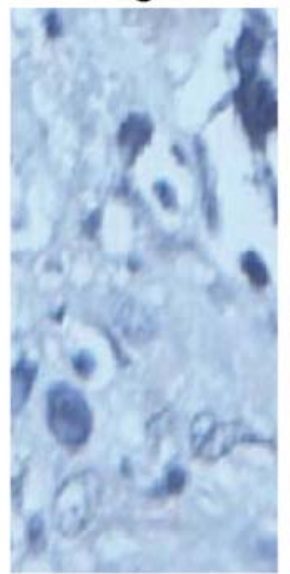

$\mathrm{D}$

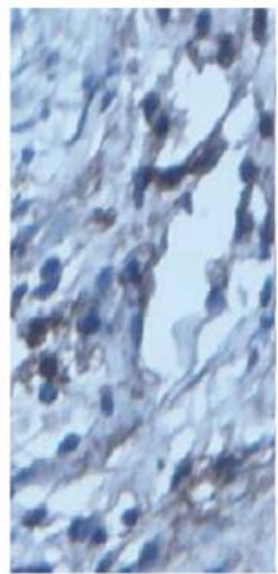

$\mathrm{E}$

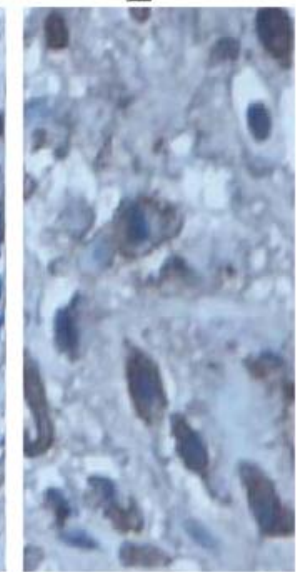

Figure 11. Immunohistochemical staining with von willebrand factor (vWF) of nude mice lung adenocarcinoma transplanted tumor tissue in each group, magnification, x400. (A) Saline group. (B) Standard rhTNF- $\alpha$ group. (C-E) High, middle, low dose experimental group.

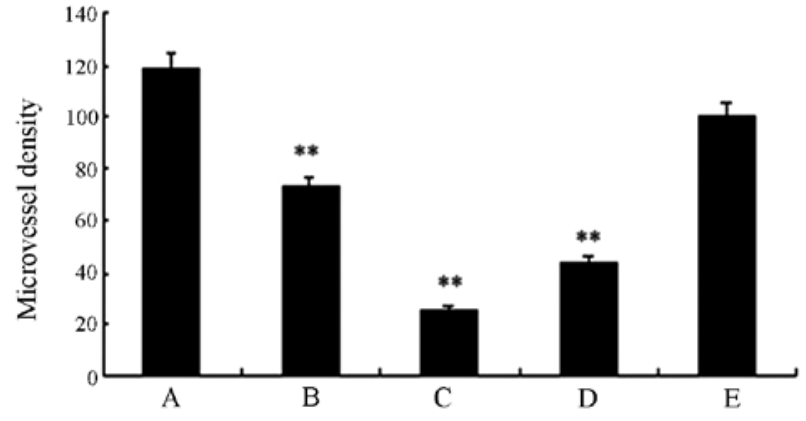

Figure 12. Microvessel density (MVD) of nude mice lung adenocarcinoma transplanted tumor tissue in each group. (B) Standard hTNF- $\alpha$ group (C-E) high-, middle- and low-dose experimental groups. *" $\mathrm{P}<0.01$, compared with the saline group.

vWF was closely associated with the multiplication of vascular endothelial cells. The adhesive protein, which was synthesized in endothelial cells was considered to be the most reliable marker of endothelial cells in culture (24-27). Fig. 11 shows the immunohistochemical result of tumor tissue identified by the immunofluorescent detection of vWF. Fig. 10 indicates that the fusion protein inhibited angiogenesis. The microvessel density (MVD) of the high- and middle-dose experimental groups and the standard hTNF- $\alpha$ group exhibited statistical significance $(\mathrm{P}<0.01)$ compared with the saline group (Fig. 12). This finding was consistent with the results obtained from immunohistochemical and H\&E staining. Thus the fusion protein was able to inhibit angiogenesis.

In situ detection of apoptosis by TUNEL. Fig. 13 shows the microscopic area of apoptotic cells in transplanted tumor tissue by TUNEL assay. The data in Fig. 14 were statistically processed. The differences in the high-dose experimental and standard hTNF- $\alpha$ groups were particularly evident. The apoptotic index reached 78.78 and $66.65 \%$, respectively, and 
A

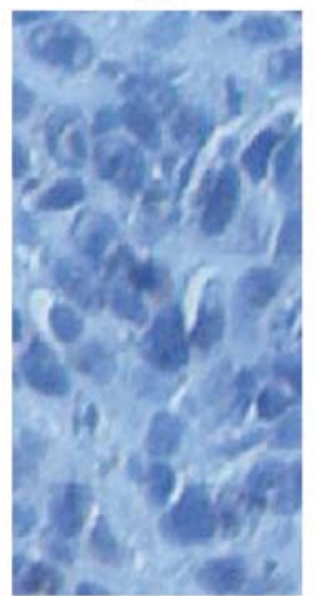

B

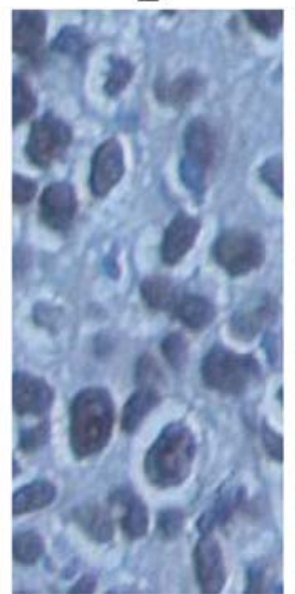

$\mathrm{C}$

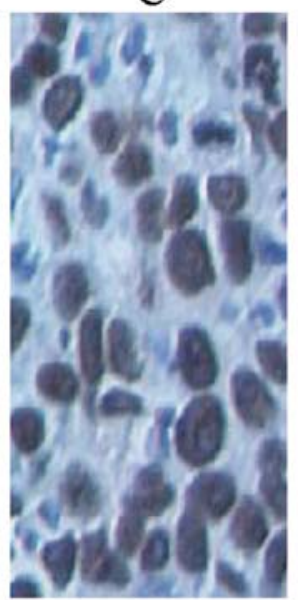

$\mathrm{D}$

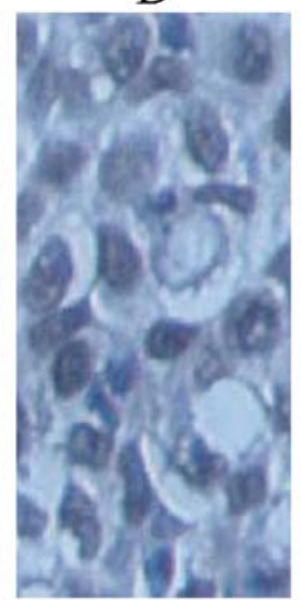

E

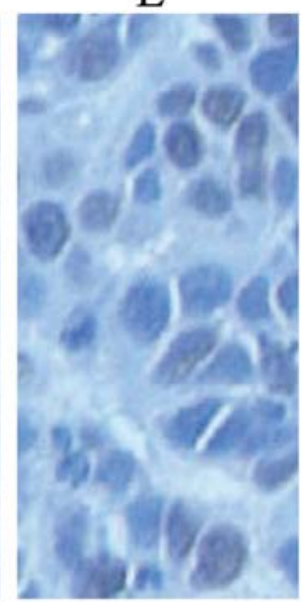

Figure 13. In situ cell death detection of tumor tissue; magnification, $\mathrm{x} 400$. Brown-colored positive apoptotic cells are evident in the (B) standard hTNF- $\alpha$ and (C and D) high- and middle-dose experimental groups, compared with the (A) saline group. (E) Low-dose experimental group.

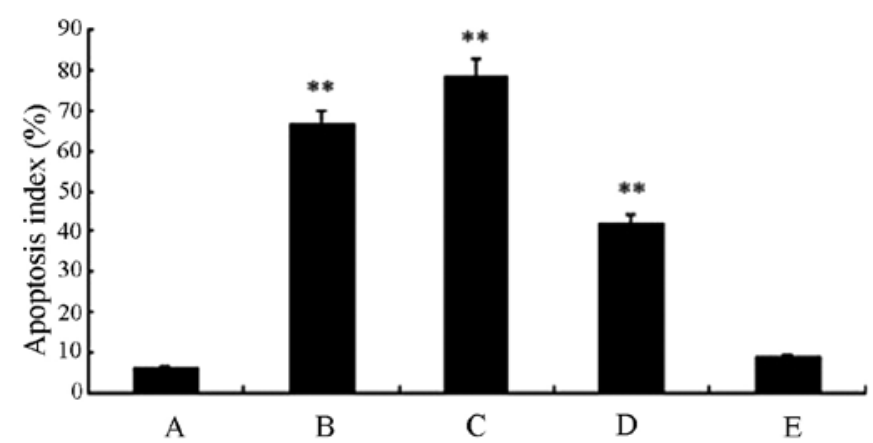

Figure 14. Apoptotic index of transplanted tumor tissue. (B) Standard hTNF- $\alpha$ group, (C-E) high-, middle- and low-dose experimental groups. ${ }^{* *} \mathrm{P}<0.01$, compared with the (A) saline group.

indicated a significant statistical difference $(\mathrm{P}<0.01)$. The apoptotic index of the middle-dose group was $42.31 \%(\mathrm{P}<0.01)$.

\section{Discussion}

Various strategies have been explored for the tumor-targeted delivery of TNF- $\alpha$ over the last two decades, such as the use of inducible or tissue-specific viral vectors for cancer gene therapy and the generation of fusion proteins specific for certain molecular cancer markers (28). Traditional chemotherapeutic drugs have high toxicity and poor tumor targeting. Molecular-targeted drugs possess advantages such as targeting, safety and durability, which are crucial in alleviating the disease. The development of medical molecular biology has led to an increase in focus on molecular-targeted treatment, a new method for treating malignant tumors (29). In a previous study, Cooke et al (30) used a genetic fusion of human recombinant TNF- $\alpha$ with MFE-23, a single-chain $\mathrm{Fv}$ antibody fragment directed against the carcinoembryonic antigen. Radiolabeled MFE-23::TNF- $\alpha$ fusion protein bound both mouse and human TNF receptor 1 in vitro and was able to localize effectively in nude mouse-bearing human LS174T xenografts. As results of that study showed, following intra- venous injection the tumor/tissue ratios achieved 24 and $48 \mathrm{~h}$, respectively, were 21:1 and 60:1. Findings of those studies showed that MFE-23::TNF- $\alpha$ provides an efficient means for systemically administered cancer therapy.

Our preliminary experiments confirm that the fusion protein has the function of killing tumor cells at the cellular level. In this experiment, the result of H\&E staining of tumor tissues, tumor weights and volume of each dose group indicated that the fusion protein exerted an inhibitory effect on tumor tissue. Further contrasting the results of the pathological section and biochemical indicator of SPF nude mouse liver, heart and kidney, the modified fusion protein was confirmed to specifically target tumor cells, inhibiting cell growth. However, damage to the liver, heart and kidney was significantly reduced. The result of tumor tissue immunohistochemical staining using vWF as the antibody showed that fusion protein fold on-MMP2-rhTNF- $\alpha$ exerted a certain inhibitory effect on angiogenesis. Detection of apoptotic cells via the TUNEL method demonstrated that the apoptotic index of the high- and middle-dose experimental group was statistically significant $(\mathrm{P}<0.01)$. It was also identified that tumor growth was markedly inhibited in the high- and middle-dose experimental groups.

Recent studies have focused on the use of different doses of fusion protein to target antitumor effect and reduce the functional damage to organs. However, large doses of fusion protein that are tolerant to the body have not been previously experimentally validated. Future studies should focus on whether modified fusion protein exerts the same inhibitory effect on other tumors besides lung adenocarcinoma. Investigation of the cellular level and the present experimental approach at an animal level, confirms that the antitumor effect of modified fold on-MMP-2-rhTNF- $\alpha$ was improved, and that the side effects were reduced.

\section{Acknowledgements}

The present study was supported by the First Batch of Science and Technology Plan in Guangdong Province (no. 2008B030301023) and the Dongguan Science and 
Technology Projects for higher education institutions (nos. 200910815264 and 2012108102016).

\section{References}

1. Jo SK, Hong JY, Park HJ and Lee SK: Anticancer activity of novel daphnane diterpenoids from Daphne genkwa through cell-cycle arrest and suppression of Akt/STAT/Src signalings in human lung cancer cells. Biomol Ther (Seoul) 20: 513-519, 2012

2. Wangari-Talbot $\mathbf{J}$ and Hopper-Borge E: Drug resistance mechanisms in non-small cell lung carcinoma. J Can Res Updates 2: 265-282, 2013.

3. Zhao P, Dai M, Chen W and Li N: Cancer trends in China. Jpn J Clin Oncol 40: 281-285, 2010.

4. Zhang Y, Wu JZ, Zhang JY, et al: Detection of circulating vascular endothelial grow th factor and matrix metalloproteinase-9 in non-small cell lung cancer using Luminex multiplex technology. Oncol Lett 7: 499-506, 2014.

5. Wang S: The promise of cancer therapeutics targeting the TNF-related apoptosis-inducing ligand and TRAIL receptor pathway. Oncogene 27: 6207-6215, 2008

6. Carswell EA, Old LJ, Kassel RL, Green S, Fiore N and Williamson B: An endotoxin-induced serum factor that causes necrosis of tumors. Proc Natl Acad Sci USA 72: 3666-3670, 1975

7. Old LJ: Tumor necrosis factor (TNF). Science 230: 630-632, 1985.

8. Van Roy M, Wielockx B, Baker A and Libert C: The use of tissue inhibitors of matrix metalloproteinases to increase the efficacy of a tumor necrosis factor/interferon gamma antitumor therapy. Cancer Gene Ther 14: 372-379, 2007.

9. Alexander HR Jr, Bartlett DL and Libutti SK: Current status of isolated hepatic perfusion with or without tumor necrosis factor for the treatment of unresectable cancers confined to liver. Oncologist 5: 416-424, 2000.

10. Grunhagen DJ, Brunstein F, ten Hagen TL, van Geel AN, de Wilt JH and Eggermont AM: TNF-based isolated limb perfusion: a decade of experience with antivascular therapy in the management of locally advanced extremity soft tissue sarcomas. Cancer Treat Res 120: 65-79, 2004.

11. Grunhagen DJ, de Wilt JH, ten Hagen TL and Eggermont AM: Technology insight: Utility of TNF-alpha-based isolated limb perfusion to avoid amputation of irresectable tumors of the extremities. Nat Clin Pract Oncol 3: 94-103, 2006.

12. Son KJ, Shin DS, Kwa T, Gao Y and Revzin A: Micropatterned sensing hydrogels integrated with reconfigurable microfluidics for detecting protease release from cells. Anal Chem 85: 11893-11901, 2013.

13. Roy R, Yang J and Moses MA: Matrix metalloproteinases as novel biomarkers and potential therapeutic targets in human cancer. J Clin Oncol 27: 5287-5297, 2009.

14. Weng Y, Cai M, Zhu J, et al: Matrix metalloproteinase activity in early-stage lung cancer. Onkologie 36: 256-259, 2013
15. Kao SJ, Su JL, Chen CK, et al: Osthole inhibits the invasive ability of human lung adenocarcinoma cells via suppression of $\mathrm{NF}-\kappa \mathrm{B}-$ mediated matrix metalloproteinase-9 expression. Toxicol Appl Pharmacol 261: 105-115, 2012.

16. Leinonen T, Pirinen R, Bohm J, Johansson R, Ropponen K and Kosma VM: Expression of matrix metalloproteinases 7 and 9 in non-small cell lung cancer. Relation to clinicopathological factors, beta-catenin and prognosis. Lung Cancer 51: 313-321, 2006.

17. Siejka A, Barabutis N and Schally AV: GHRH antagonist inhibits focal adhesion kinase (FAK) and decreases expression of vascular endothelial growth factor (VEGF) in human lung cancer cells in vitro. Peptides 37: 63-68, 2012.

18. Shao W, Wang W, Xiong XG, et al: Prognostic impact of MMP-2 and MMP-9 expression in pathologic stage IA non-small cell lung cancer. J Surg Oncol 104: 841-846, 2011.

19. Qian Q, Wang Q, Zhan P, et al: The role of matrix metalloproteinase 2 on the survival of patients with non-small cell lung cancer: a systematic review with meta-analysis. Cancer Invest 28: 661-669, 2010

20. Desmard M, Amara N, Lanone S, Motterlini R and Boczkowski J: Carbon monoxide reduces the expression and activity of matrix metalloproteinases 1 and 2 in alveolar epithelial cells. Cell Mol Biol (Noisy-le-grand) 51: 403-408, 2005.

21. Chauhan V, Breznan D, Thomson E, Karthikeyan S and Vincent R: Effects of ambient air particles on the endothelin system in human pulmonary epithelial cells (A549). Cell Biol Toxicol 21: 191-205, 2005.

22. Pardo A, Gibson K, Cisneros J, et al: Up-regulation and profibrotic role of osteopontin in human idiopathic pulmonary fibrosis. PLoS Med 2: e251, 2005.

23. Weidner N: Current pathologic methods for measuring intratumoral microvessel density within breast carcinoma and other solid tumors. Breast Cancer Res Treat 36: 169-180, 1995.

24. Mendolicchio GL and Ruggeri ZM: New perspectives on von Willebrand factor functions in hemostasis and thrombosis. Semin Hematol 42: 5-14, 2005.

25. Cao C, Qi Y, Chen W, Zhu Y and Chen X: Effects of IKKe on oxidised low-density lipoprotein-induced injury in vascular endothelial cells. Heart Lung Circ 22: 366-372, 2013.

26. Ulger H, Karabulut AK and Pratten MK: Labelling of rat endothelial cells with antibodies to vWF, RECA-1, PECAM-1, ICAM-1, OX-43 and ZO-1. Anat Histol Embryol 31: 31-35, 2002.

27. Ruggeri ZM: Structure of von Willebrand factor and its function in platelet adhesion and thrombus formation. Best Pract Res Clin Haematol 14: 257-279, 2001.

28. Cai W, Kerner ZJ, Hong H and Sun J: Targeted cancer therapy with tumor necrosis factor-alpha. Biochem Insights 2008: 15-21, 2008.

29. Gaughan EM and Costa DB: Genotype-driven therapies for non-small cell lung cancer: focus on EGFR, KRAS and ALK gene abnormalities. Ther Adv Med Oncol 3: 113-125, 2011.

30. Cooke SP, Pedley RB, Boden R, Begent RH and Chester KA: In vivo tumor delivery of a recombinant single chain $\mathrm{Fv}::$ tumor necrosis factor-alpha fusion [correction of factor: a fusion] protein Bioconjug Chem 13: 7-15, 2002. 